\title{
PERANCANGAN SISTEM INFORMASI KEUANGAN PADA UNIT KOPERASI SIMPAN PINJAM
}

\author{
Luki Hernando \\ Fakultas Teknologi Informasi, Institut Teknologi Batam, \\ Jl. Gajah Mada Kompleks Vitka City, Tiban Ayu - Sekupang - Batam \\ Email : luki.hernando04@gmail.com
}

\begin{abstract}
Research by the author at Cooperative Center District aims to determine the presence of data processing system finance especially in terms of savings and loans, installment loans and data processing cooperative members that was running at Cooperative Center District. Therefore, by implementing a new system that can optimize data processing system of finance in the savings and loans unit and can improve employee performances and improve the quality of higher cooperative. The research was conducted by collecting data, direct observation, and laboratory research in designing computer programs and the preparation of reports. The importance of the conclusion, with this new system will be able to assist the employee in performing data processing of finance in the savings and loans unit Cooperative Center and can provide information and reports quickly and as required.
\end{abstract}

Key words : Information Systems, Savings and Loans, Cooperative

\begin{abstract}
Abstrak
Penelitian yang penulis lakukan pada Pusat Koperasi ini bertujuan untuk mengetahui sistem pengolahan data keuangan terutama dalam hal simpan pinjam, pembayaran angsuran pinjaman dan pengolahan data anggota koperasi yang ada pada Koperasi. Sehingga dengan mengimplementasikan sistem yang baru dapat mengoptimalkan sistem pengolahan keuangan pada unit simpan pinjam dan dapat meningkatkan kinerja karyawan serta meningkatkan mutu dari koperasi tersebut. Penelitian ini dilakukan dengan mengumpulkan data-data, observasi langsung, dan penelitian laboratorium komputer dalam merancang program dan penyusunan laporan. Maka didapat kesimpulan, dengan adanya sistem baru ini akan dapat membantu karyawan dalam melakukan pengolahan data keuangan pada unit simpan pinjam dan dapat menyediakan informasi serta laporan-laporan yang dibutuhkan dengan cepat dan sesuai dengan yang dibutuhkan.
\end{abstract}

Kata kunci $\quad$ : $\quad$ Sistem Informasi, Simpan Pinjam, Koperasi 


\section{PENDAHULUAN}

Salah satu contoh penerapan teknologi informasi adalah penggunaan system informasi untuk mengolah data menjadi suatu informasi yang lebih akurat. Suatu sistem informasi sangat membantu dalam kemudahan penyampaian dan penerimaan informasi, karena setiap sistem informasi mempunyai peran untuk memberikan informasi kepada user dengan mengolah data-data yang ada,sehingga menghasilkan informasi yang akurat untuk user.

Koperasi "Simpan pinjam di pusat koperasi merupakan salah satu unit pelaksana kesejahteraan anggota yang bertujuan memberi kesempatan kepada anggotanya memperoleh pinjaman dengan mudah dan bunga ringan. Koperasi ini menghimpun dana dari anggotanya yang kemudian menyalurkan kembali dana tersebut kepada para anggotanya. Koperasi juga dapat menjadi pilihan untuk menginvestasikan dana (menabung).

Adapun anggota koperasi ini adalah hampir semua karyawan yang ada di koperasi.Saat ini pengolahan data koperasi masih manual dalam penyajian transaksi simpan pinjam, pengolahan data anggota. Sering terjadinya masalah keterlambatan pencarian transaksi yang disebabkan karena arsip mengalami penumpukan. Pada membuat laporan tahunan. Keterbatasan daya ingat manusia juga sering membuat kesalah pahaman anggota koperasi terkait pembayaran angsuran pinjaman. Adapun anggota koperasi ini adalah hampir semua karyawan yang ada di. Saat ini pengolahan data koperasi di koperasi masih manual dalam penyajian transaksi simpan pinjam, pengolahan data anggota. Sering terjadinya masalah keterlambatan pencarian transaksi yang disebabkan karena arsip mengalami penumpukan. Pada membuat laporan tahunan. Keterbatasan daya ingat manusia juga sering membuat kesalah pahaman anggota koperasi terkait pembayaran angsuran pinjaman.

Berdasarkan permasalahan di atas, maka perlu dibangun sebuah system informasi yang mampu menangani pengolahan dana simpan pinjam, pengolahan data anggota dan perhitungan kas. Dengan adanya system informasi ini diharapkan dapat digunakan untuk mempermudah dalam penyusunan laporan, perhitungan yang akurat dan benar serta data terorganisasi dengan baik, tersimpan dengan aman dan mudah ditelusuri. Dengan adanya pertimbangan maka dapat di rancang sistem informasi yang berjudul tentang " Perancangan Sistem Informasi Keuangan Pada Unit Koperasi Simpan Pinjam "

\section{METODE PENELITIAN}

Kerangka kerja ini merupakan langkahlangkah yang akan di lakukan dalam penyelesaian masalah yang akan di bahas.

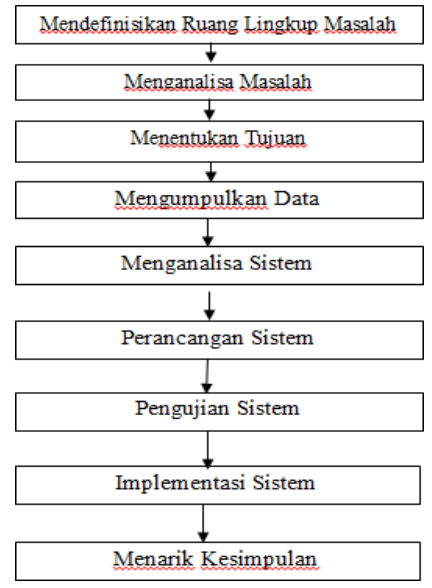

Gambar 1. Kerangka Kerja

Pada sub bab ini akan diuraikan dan dijelaskan kerangka kerja penelitian berdasarkan gambar diatas:
1. Mendefinisikan Ruang Lingkup Masalah
Ruang lingkup masalah yang akan diteliti harus ditentukan terlebih 
dahulu, karena tanpa menentukan serta mendefinisikan batasan masalah yang akan diteliti, maka tidak akan pernah didapat suatu solusi dan pemecahan yang terbaik dari masalah tersebut. Jadi langkah pertama ini adalah langkah awal yang terpenting dalam penulisan ini.

2. Menganalisa Masalah

Langkah analisis masalah adalah untuk dapat memahami masalah yang telah ditentukan ruang lingkup atau batasannya. Dengan menganalisa masalah yang telah ditentukan tersebut, maka diharapkan masalah dapat dipahami dengan baik. Metode analisa yang dipakai bertujuan untuk menganalisis kebutuhan dalam mengambil keputusan yang optimal yang telah ditetapkan dengan menggunakan kriteria-kriteria yang telah ditentukan.

3. Menentukan Tujuan

Berdasarkan pemahaman dari masalah, maka ditentukan tujuan yang akan dicapai dari penulisan ini. Pada tujuan ini ditentukan target yang dicapai, terutama yang dapat mengatasi masalah-masalah yang ada.

4. Pengumpulan data

Setelah mempelajari ruang lingkup masalah, menganalisa masalah dan menentukan tujuan, makan akan di lakukan pengumpulan data yang akan dibahas yang teriri dari berbagai kriteria yaitu dengan cara penelitian perpustakaan (library research) dan penelitian laboratorium (laboratory research).

5. Menganalisa Sistem

Setelah dilakukan metode pengumpulan data, maka akan dilaksanakan tahapan berikutnya yaitu menganalisa sistem yang akan memudakan penulis dalam pembuatan sistem.

6. Perancangan Sistem

Perancangan sistem bertujuan untuk memudahkan penulis dalm pembuatan program, seperti merancang output dan input dari suatu sistem dan akan melakukan pembangunan sistem yang akan di buat.

7. Pengujian Sistem

Pada Tahap pengujian sistem ini dilakukan pengujian terhadap sistem yang telah di bangun, mencari adakah kesalahan, debug atau error yang masih ada di dalam suatu sistem,yang bertujuan selanjutnya agar bisa di perbaiki sehingga sistem ini bisa digunakan dengan baik.

8. Implementasi Sistem

Tahapan berikutnya yang akan dilakukan di dalam penelitian adalah melakukan implementasi dari sistem yang telah dibuat. Pada tahapan implementasi sistem ini aplikasi akan di buat setupny dan akan di instal pada komputer untuk digunakan oleh si pemakai atau user.

9. Menarik kesimpulan merupakan suatu cara untuk mengetahui apakah sistem yang dirancang sesuai dengan apa yang diharapkan. Menarik Kesimpulan dilakukan agar dapat membandingkan hasil yang didapat

\section{HASIL DAN PEMBAHASAN Analisa Sistem Informasi Yang Sedang Berjalan}

Analisa sistem adalah penguraian dari sistem informasi yang utuh ke dalam bagian komponen - komponen, dengan maksud untuk mengidentifikasi dan mengevaluasi permasalahan permasalahan, hambatan - hambatan yang terjadi serta kebutuhan - kebutuhan yang diharapkan sehingga dapat diusulkan perbaikan. (Eka Iswandy, 2016).

Analisa merupakan suatu kegiatan yang bertujuan untuk mempelajari serta mengevaluasi suatu bentuk permasalahan yang ada pada sebuah sistem. Dalam analisa sistem akan ditemukan masalah yang mungkin akan mempengaruhi kerja sistem. Agar sistem yang dirancang dapat berjalan dengan mestinya, perlu dilakukan analisis terhadap kinerja sistem yang pada 
akhirnya bertujuan untuk pengembangan sistem.

\section{Gambaran Umum Sistem}

Sebuah sistem terdiri dari berbagai unsur yang saling melengkapi dalam mencapai tujuan dan sasaran. Unsur-unsur yang terdapat dalam sistem itulah yang disebut dengan subsistem. Subsistemsubsistem tersebut harus saling berhubungan dan berinteraksi melalui komunikasi yang relevan sehingga sistem dapat bekerja secara efektif dan efisien (Eka Iswandy, 2015).

Sistem pengolahan data keuangan pada unit simpan pinjam koperasi yang ada belum menggunakan komputer. Sistem yang sedang berjalan pada saat ini melibatkan anggota koperasi, bagian administrasi, dan pimpinan. Dimana hampir semua proses yang terjadi dilakukan oleh bagian administrasi yaitu mulai dari membuat dan menginput data anggota, simpanan, pinjaman, dan angsuran, hingga pembuatan laporan.

\section{Aliran Sistem Informasi Yang Diusulkan}

Sistem baru yang dirancang tidak merubah sistem yang ada secara keseluruhan. Pada sistem yang diusulkan proses penyimpanan datanya dilakukan secara komputerisasi dengan menggunakan database dan aplikasi yang khusus.

Uraian dari system registrasi anggota yang diusulkan adalah sebagai berikut :

a. Untuk pendaftaran awalnya bagian administrasi memberikan form pendaftaran kepada anggota dan selanjutnya diisi oleh anggota. Yang selanjutnya menghasilkan form pendaftaran yang telah diisi berikut dengan dokumen persyaratannya. Dan kemudian diserahkan kembali ke bagian administrasi. b. Bagian administrasi menginput pendaftaran anggota ke dalam program. Sehingga menghasilkan data anggota dan selanjutnya dibuatkan kartu tanda anggotanya. Kemudian kartu anggota tersebut diberikan kepada pimpinan untuk diacc dan menghasilkan kartu tanda anggota valid.

c. Pimpinan memberikan kartu tanda anggota valid tersebut ke bagian administrasi untuk selanjutnya diserahkan ke anggota.

d. Bagian administrasi membuat laporan anggota sebanyak 2 rangkap dan diberikan kepada pimpinan untuk di Acc. Dan menghasilkan laporan anggota ACC. Satu rangkap diarsip oleh pimpinan dan satu rangkap lagi diarsip oleh bagian administrasi.

\section{ASI Simpanan Anggota Yang Diusulkan}

Uraian dari system simpanan anggota yang diusulkan adalah sebagai berikut :

a. Untuk simpanan awalnya anggota memberikan kartu anggota ke bagian administrasi. Dan bagian administrasi menginput data simpanan.

b. Setelah itu bagian administrasi membuat kwitansi simpanan sebanyak 2 rangkap. Satu rangkap diarsip dan satu rangkap lagi diberikan kepada anggota berikut dengan kartu anggota tadi.

c. Bagian administrasi membuat laporan simpanan sebanyak 2 rangkap dan diberikan kepada pimpinan untuk di Acc. Dan menghasilkan laporan data simpanan, laporan data simpanan anggota ACC. Satu rangkap diarsip oleh pimpinan dan satu rangkap lagi diarsip oleh bagian administrasi. 


\section{ASI Pinjaman Anggota Yang Diusulkan}

Uraian dari system pinjaman anggota yang diusulkan adalah sebagai berikut :

a. Untuk pinjaman awalnya anggota memberikan kartu anggota ke bagian administrasi berikut dengan pengajuan pinjaman.

b. Data pengajuan pinjaman tersebut diberikan kepada pimpinan untuk diAcc. Sehingga menghasilkan data pengajuan pinjaman Acc. Dan dikembalikan lagi ke bagian administrasi. Dan bagian administrasi menginput pinjaman tersebut.

c. Setelah itu bagian administrasi membuat kwitansi pinjaman sebanyak 2 rangkap. Satu rangkap diarsip dan satu rangkap lagi diberikan kepada anggota berikut dengan kartu anggota tadi.

d. Bagian administrasi membuat laporan pinjaman, laporan data pengambilan sebanyak 2 rangkap dan diberikan kepada pimpinan untuk di Acc. Dan menghasilkan laporan pinjaman ACC. Satu rangkap diarsip oleh pimpinan dan satu rangkap lagi diarsip oleh bagian administrasi.

\section{ASI Angsuran Anggota Yang Diusulkan}

Uraian dari system pengeluaran yang diusulkan adalah sebagai berikut :

a. Untuk pengeluaran bagian administrasi mencatat data pengeluaran yang diperoleh dari kwitansi-kwitansi pembelian ke dalam buku besar. Dan kemudian menghasilkan data pengeluaran

b. Bagian administrasi membuat laporan pengeluaran sebanyak 2 rangkap dan diberikan kepada pimpinan untuk di Acc. Dan menghasilkan laporan angsuran ACC. Satu rangkap diarsip oleh pimpinan dan satu rangkap lagi diarsip oleh bagian administrasi.

\section{Context Diagram}

CD memperlihatkan sistem yang dirancang secara keseluruhan, semua external entity harus digambarkan sedemikian rupa, sehingga terlihat data yang mengalir pada input-proses-output (Rita Afyenni, 2014).

Untuk mendapatkan gambaran umum mengenai suatu sistem yang akan dirancang dapat melalui penjabaran context diagram. Dimana dalam contex diagram tersebut terdiri dari beberapa entity dan terdiri dari sebuah proses yang disebut Sistem Informasi Keuangan pada Unit Koperasi Simpan Pinjam.

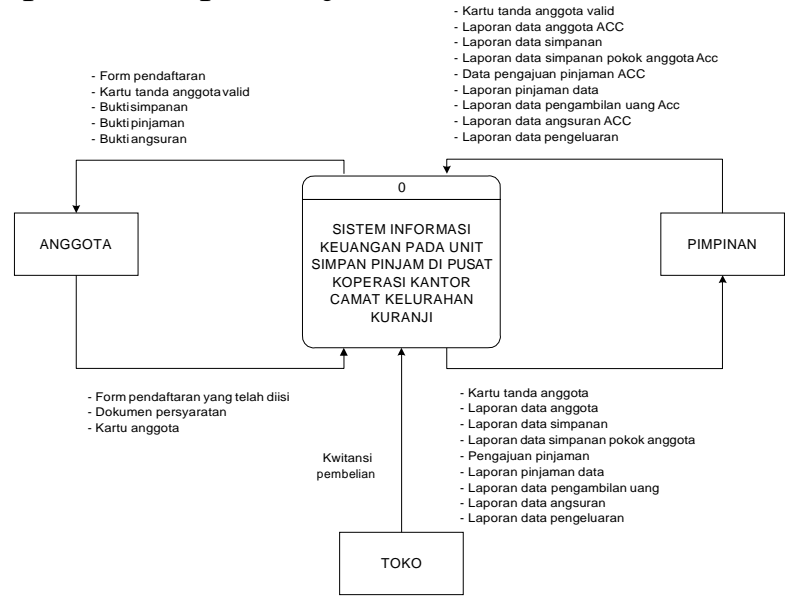

Gambar 4.11 Context Diagram

\section{Data Flow Diagram}

Alat utama untuk merepresentasikan proses komponen sistem dan arus data di antaranya adalah data flow diagram (DFD). Data flow diagram menawarkan model grafis logis dari arus informasi, mempartisi sistem menjadi modul yang menunjukkan tingkat detail yang dapat diatur. Ini secara ketat menentukan proses atau transformasi yang terjadi di dalam setiap modul dan antarmuka yang ada di antara keduanya (Cosmas Eko Suharyanto et all, 2017).

Data Flow Diagram (DFD) digunakan untuk menggambarkan arus data suatu sistem yang telah ada atau sistem baru yang akan dikembangkan secara logika. 


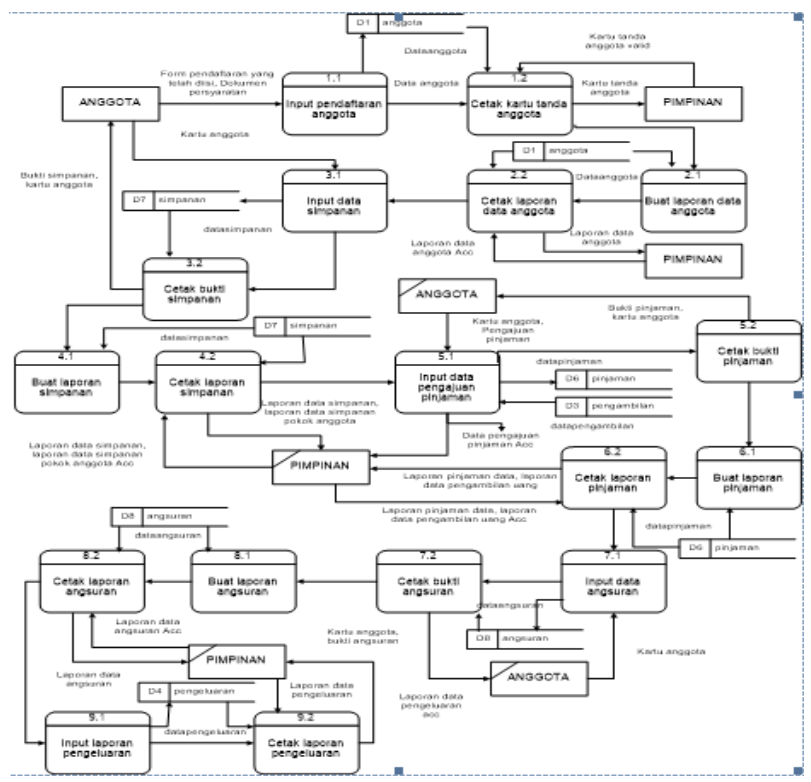

Gambar 4.12 . DFD Level 1

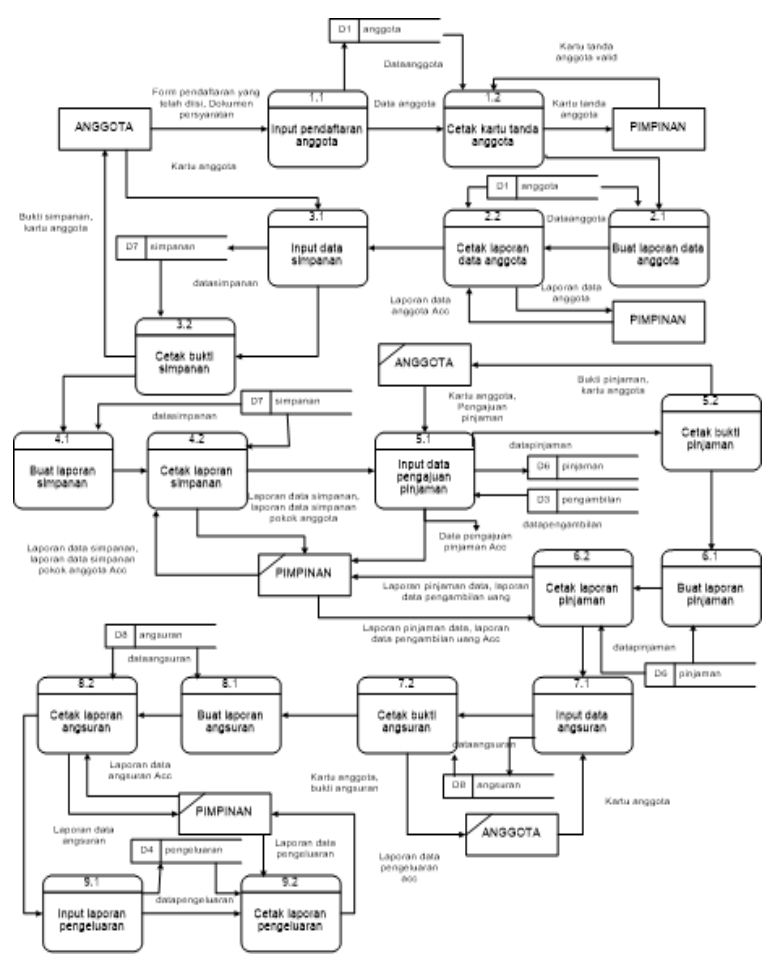

Gambar 4.12 . DFD Level 2
ERD (Entity Relationship Diagram) adalah model teknik pendekatan yang menyatakan atau menggambarkan hubungan suatu model. Didalam hubungan ini tersebut dinyatakan yang utama dari ERD adalah menunjukan objek data (Entity) dan hubungan (Relationship), yang ada pada Entity berikutnya (Eka Wida Fridayanthie and Tias Mahdiati, 2016).

Pada model relational hubugan antar file di relasikan dengan kunci relasi yang merupakan kunci utama dari masingmasing file. Perancangan database yang tepat menyebabkan paket program akan bekerja lebih optimal.

Berikut ini bentuk Entity Relationship Diagram (ERD) dari Sistem Informasi Keuangan pada Unit Koperasi Simpan Pinjam:

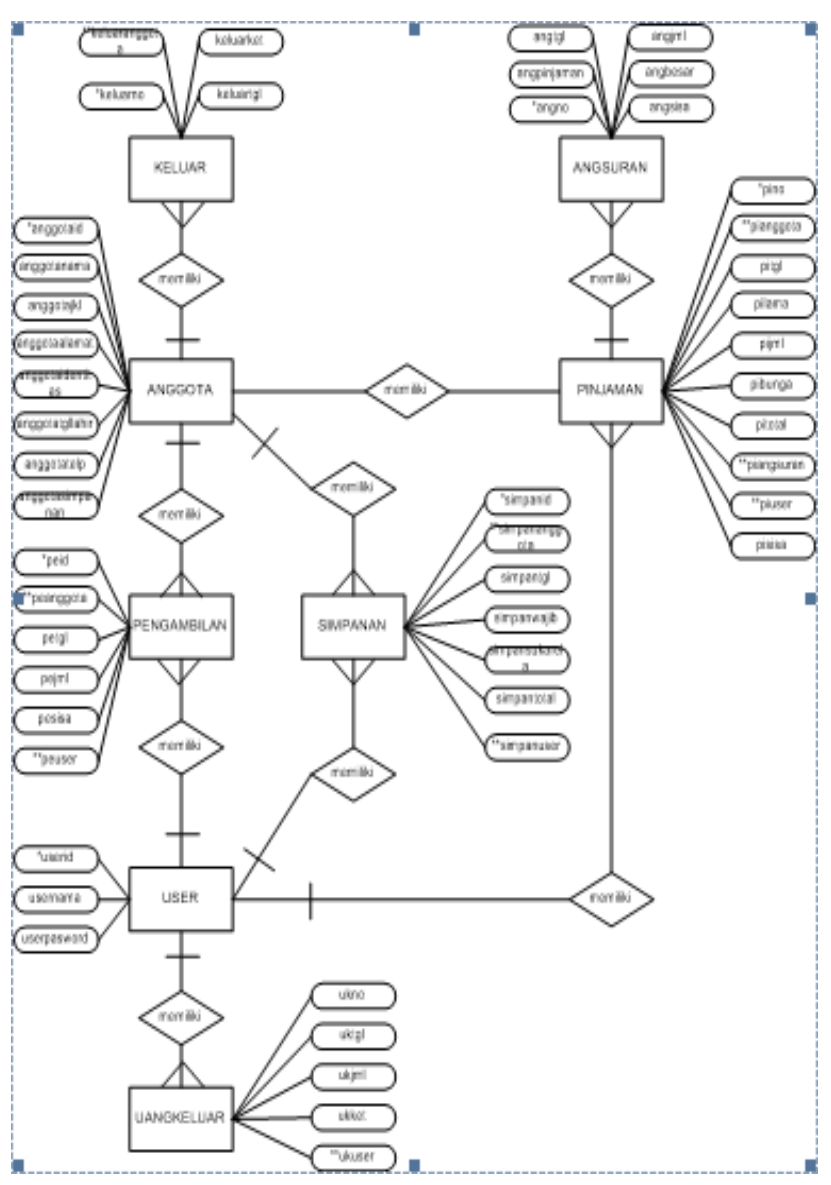

\section{Entity Relationship Diagram}




\section{Gambar 4.14 Entity Relationship Diagram}

\section{Rancangan Output}

Desain output merupakan bentuk keluaran yang dihasilkan dari pengentrian data. Adapun bentuk disain output yang dirancang adalah sebagai berikut :

1. Laporan Data Anggota Koperasi

KOPERASI SIMPAN PINJAM

\begin{tabular}{|c|c|c|c|c|c|c|c|c|}
\hline \multicolumn{9}{|c|}{ LAPORAN DATA ANGGOTA } \\
\hline No & $\begin{array}{c}\text { KODE } \\
\text { ANGGOTA }\end{array}$ & NAMA & $\begin{array}{c}\text { JENIS } \\
\text { KELAMIN }\end{array}$ & ALAMAT & \begin{tabular}{|l} 
JENIS \\
IDENTITAS
\end{tabular} & TGL LAHIR & TELP & $\begin{array}{c}\text { SIMPANAR } \\
\text { POKOK }\end{array}$ \\
\hline$x(5)$ & $x(5)$ & $\begin{array}{c}x(30) \\
\end{array}$ & $\begin{array}{l}x(30) \\
\end{array}$ & $\times(30)$ & $\times(30)$ & 99-99-9999 & $x_{(15)}$ & $9(9)$ \\
\hline$x_{(5)}$ & $\mathrm{x}(5)$ & $x(30)$ & $x(30)$ & $x(30)$ & $x(30)$ & $\sum_{99-99-9999}$ & $x_{(15)}$ & $L_{9(9)}$ \\
\hline
\end{tabular}

$\underset{\text { Padang, 99-99-9999 }}{\text { Pimpinan }}$

2. Laporan Data Simpanan

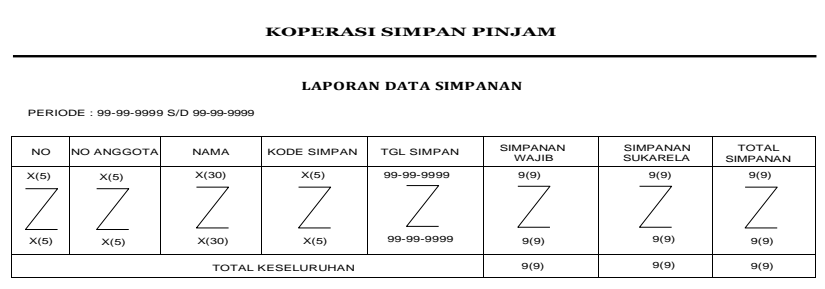

Padang, 99-99-9999
Pimpinan

$x(50)$

3. Laporan Data Simpanan Pokok Anggota

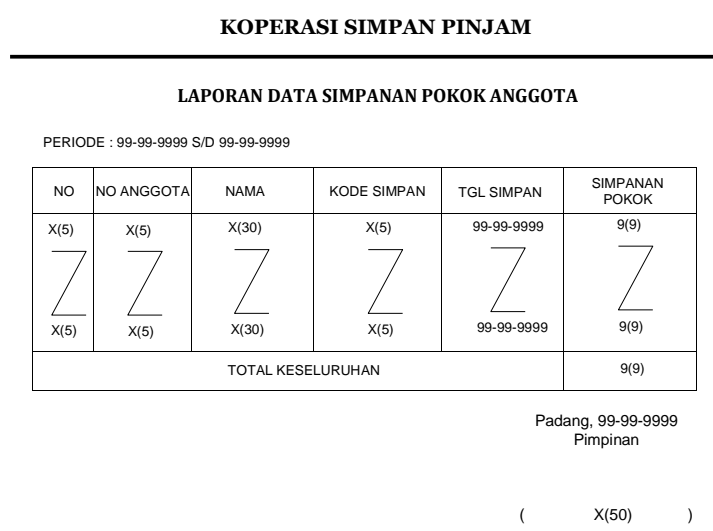

4. Laporan Data Pengambilan Uang

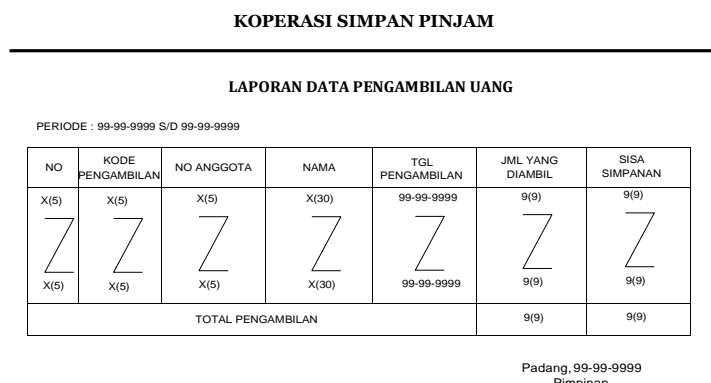

5. Laporan Data Data Pinjaman

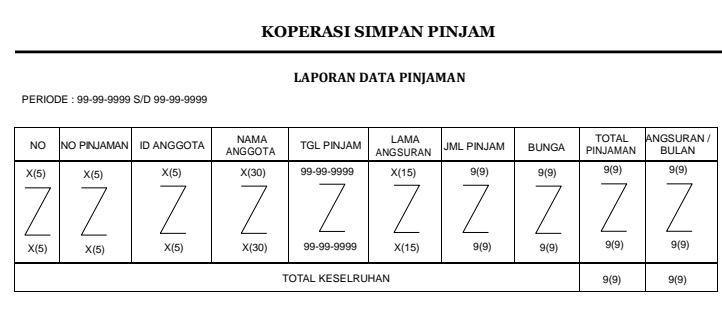

6. Bukti Pinjaman

KOPERASI SIMPAN PINJAM

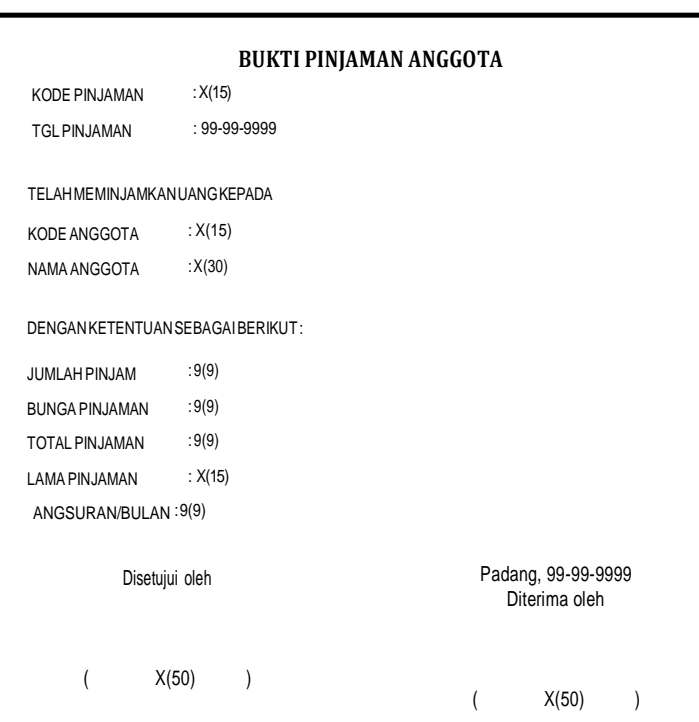

7. Bukti Angsuran 


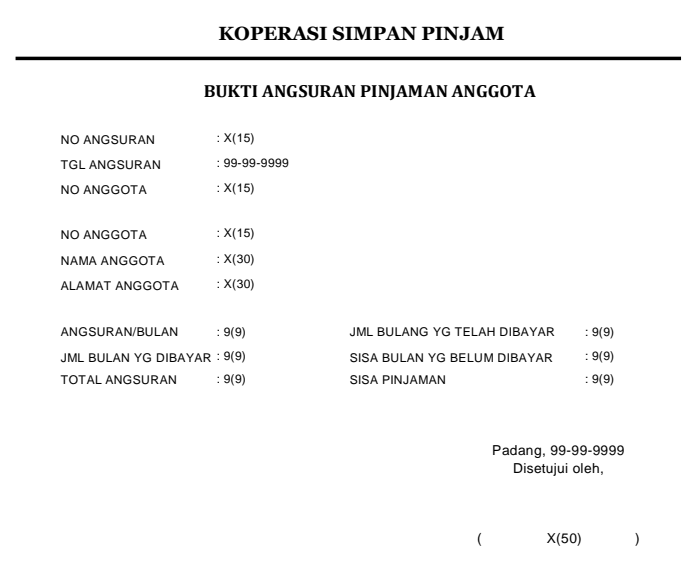

Untuk lebih jelasnya dapat dilihat pada gambar berikut :

\section{Form Login}

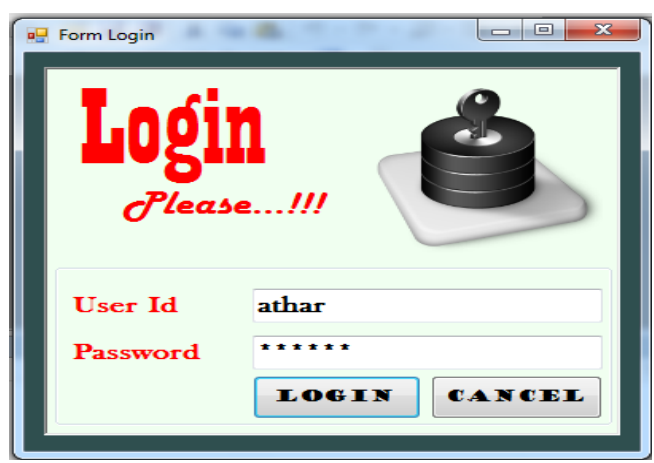

8. Laporan Data Angsuran

KOPERASI SIMPAN PINJAM

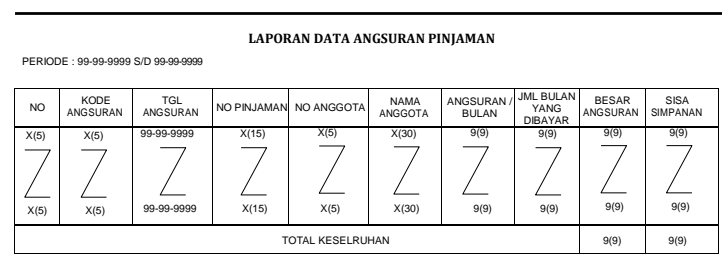

Padang, 99.9.9.999
Primpinan

\section{Laporan Data Pengeluaran}

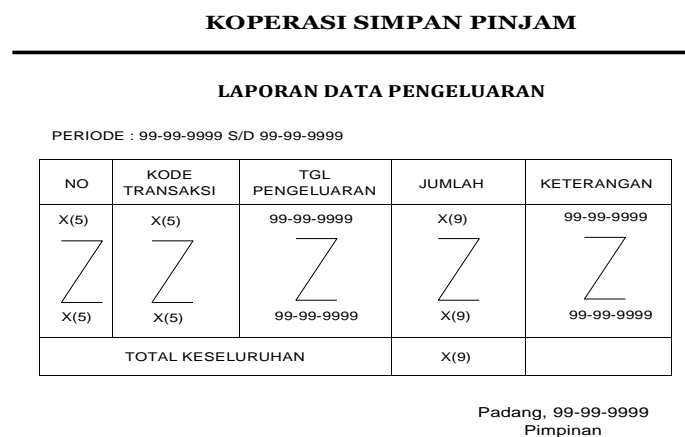

Rancangan Design Input

Rancangan input berguna untuk mengisikan data, mengkoreksi data serta menghapus data yang tidak diperlukan sehingga tercipta laporan yang tepat dan sesuai dengan informasi yang dibutuhkan.

\section{Form Menu}

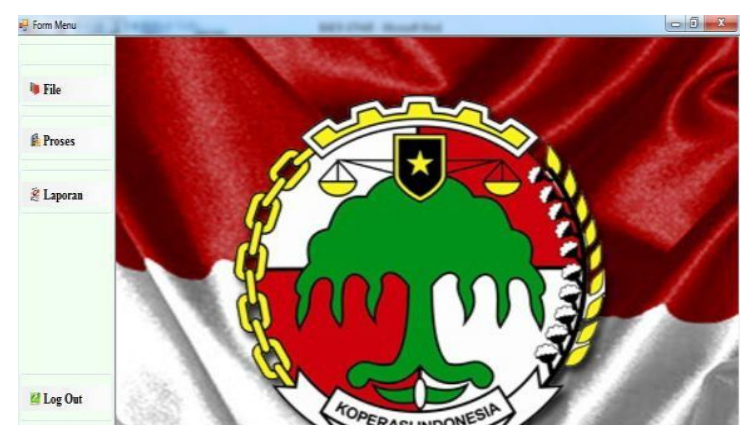

3. Form Anggota

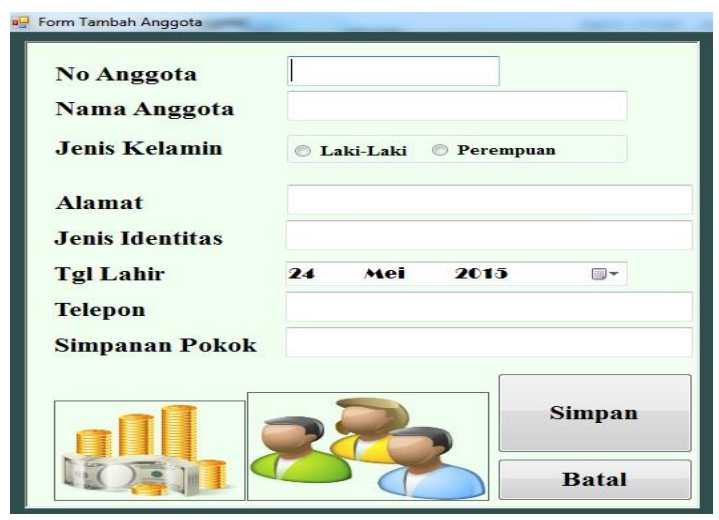

4. Form Simpanan 


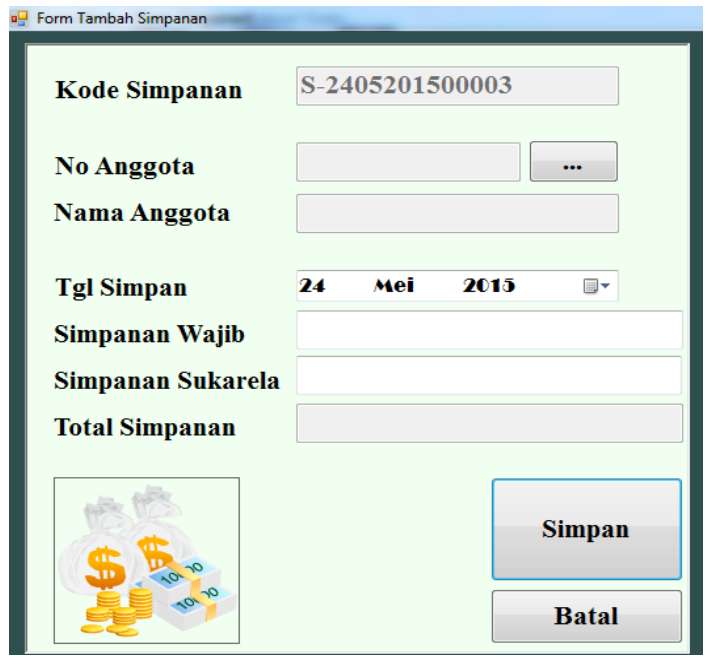

7. Form Angsuran

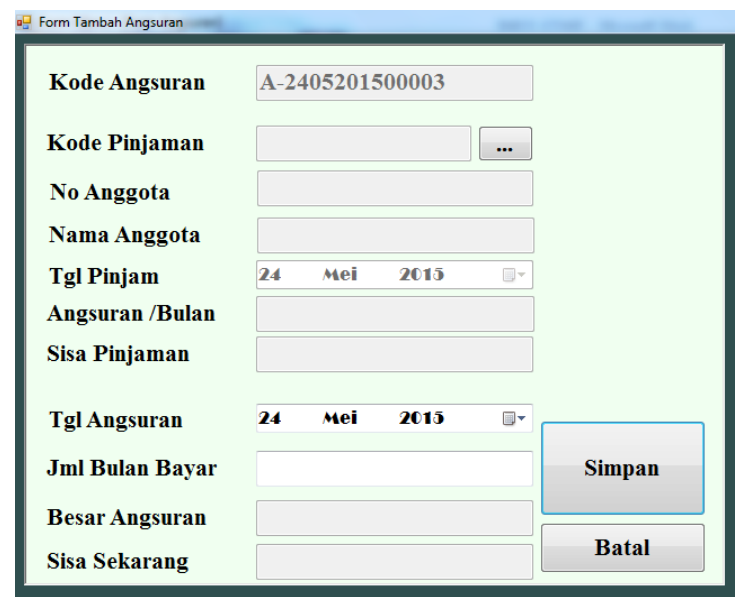

5. Form Pengambilan

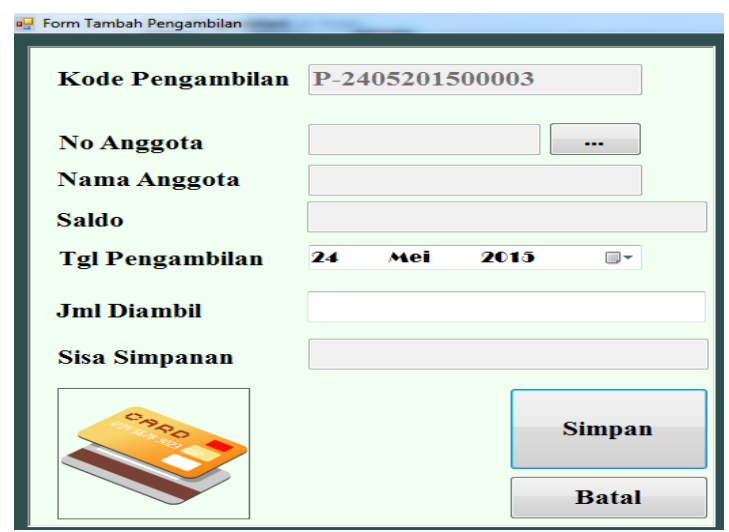

8. Form Pengeluaran Koperasi

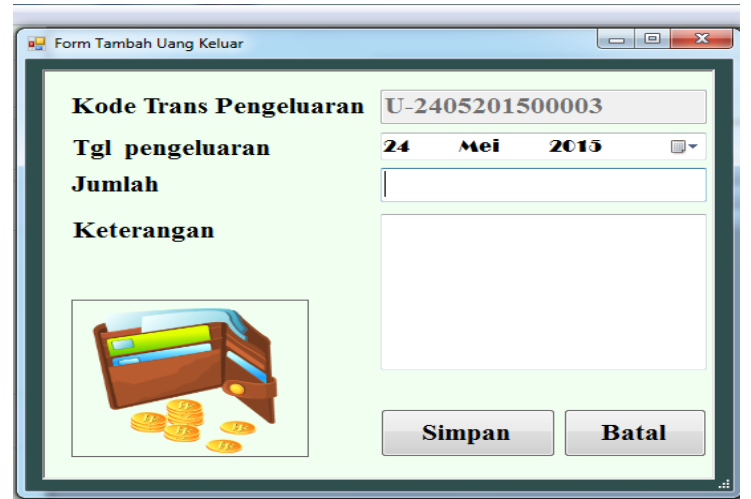

6. Form Pinjaman

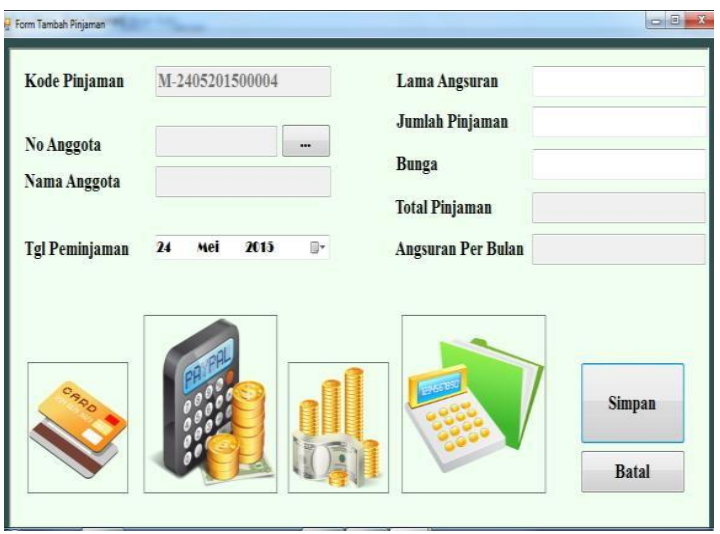

9. Form Anggota Keluar 


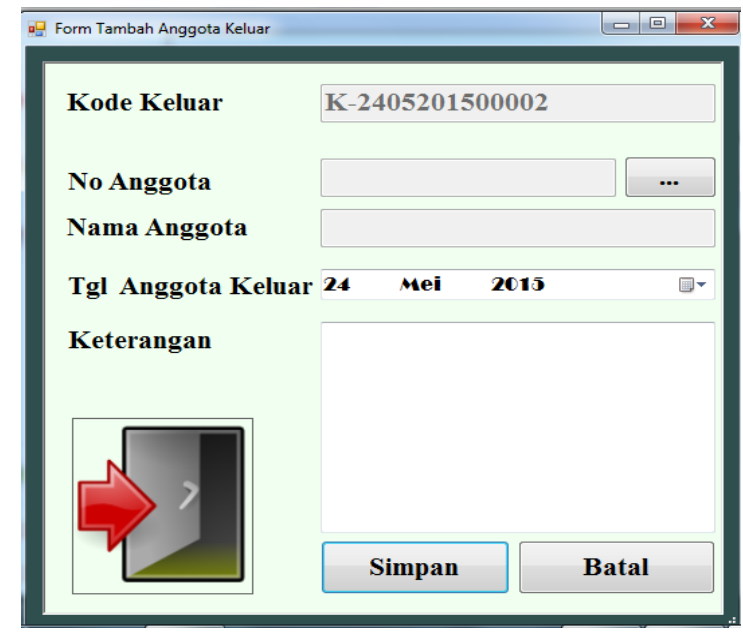

\section{SIMPULAN}

Berdasarkan penelitian yang telah dilakukan terhadap permasalahan mengenai sistem informasi keuangan pada unit simpan pinjam, dan dilandasi dengan teori-teori serta didukung oleh sarana yang dibutuhkan dalam penelitian serta solusi yang dibutuhkan dari permasalahan tersebut. Maka penulis dapat mengambil beberapa kesimpulan yaitu:

1. Sistem informasi keuangan pada unit simpan pinjam yang sedang berjalan belum optimal. Karena sistem informasi saat ini tidak sepenuhnya menggunakan komputerisasi yang didukung database, sehingga mengakibatkan lambatnya ketersediaan informasi serta penyimpanan data juga kurang efektif.

2 Dengan adanya sistem informasi yang baru data dapat terjamin keakuratannya sesuai dengan yang diharapkan.

3. Dengan adanya sistem informasi yang baru ini maka dapat mempermudah pihak koperasi dalam melakukan pengolahan data keuangan terutama dalam hal simpan pinjam, pembayaran angsuran pinjaman dan pengolahan data anggota koperasi.

4. Dapat menghasilkan laporan sesuai dengan kebutuhan pihak koperasi karena tersedianya media penyimpanan data yang dapat dengan cepat memproses pembuatan dari laporan yang dibutuhkan.

5. Penerapan sistem informasi ini akan membantu dalam mengambil keputusan dengan menganalisa laporan yang dihasilkan.

\section{UCAPAN TERIMAKSIH}

Syukur Alhamdulillah penulis panjatkan atas kehadiran Allah SWT, Yang memiliki keistimewaan dan pemberian segala kenikmatan besar, baik nikmat iman, kesehatan dan kekuaran didalam melakukan penelitian ini. Selawat dan salam senantiasa tercurahkan kepada Sayyidina Muhammada SAW.

Pada kesempatan ini penulis menyampaikan rasa terimakasih kepada

\section{DAFTAR PUSTAKA}

Eka Iswandy, 2016. Analisa Dan Perancangan Sistem Informasi Penagihan Purchasing Order Customer Studi Kasus Pada Cv. Vertical Cipta Relasi Padang Dengan Metode Centralized Data Processing.

Eka Iswandy, 2015. Sistem Penunjang Keputusan Untuk Menentukan Penerimaan Dana Santunan Sosial Anak Nagari Dan Penyalurannya Bagi Mahasiswa Dan Pelajar Kurang Mampu Di Kenagarian Barung - Barung Balantai Timur.

Rita Afyenni, 2014. Perancangan Data

Flow Diagram Untuk Sistem Informasi Sekolah (Studi Kasus Pada Sma Pembangunan Laboratorium Unp).

Cosmas Eko Suharyanto et all, 2017. Perancangan Sistem Informasi Penggajian Terintegrasi Berbasis Web (Studi Kasus di Rumah Sakit St. Elisabeth). 
Eka Wida Fridayanthie And Tias Mahdiati, 2016. Rancang Bangun Sistem Informasi Permintaan Atk Berbasis Intranet (Studi Kasus: Kejaksaan Negeri

Rangkasbitung). 